\title{
Isomaltulose as an alternative to sucrose in the composition of Turkish delight (lokum)
}

\author{
Raina Hadjikinova ${ }^{1 *}$ and Yusuf Hasan $^{1}$ \\ ${ }^{1}$ Department of tobacco, sugar, vegetable and essential oils, Faculty of Technology, University of Food Technologies, Plovdiv, Bulgaria
}

\begin{abstract}
Turkish delight is a confectionery product that differs from the others with its characteristic soft and jelly-like consistency. The main ingredients used in its production are sugar, wheat starch and glucose syrup. In recent years, there has been a tendency to increase consumer interest in so-called functional foods. This encourages confectionery manufacturers to look for a suitable alternative for partial or complete replacement of sucrose in the composition. One of the newest alternatives to sucrose is isomaltulose. It differs from other sugars by its low glycemic index and its non-cariogenicity. The aim of the present study was to establish the influence of isomaltulose, as a substitute for sucrose in the composition of „Ordinary “and „Extra "Turkish delight, on their main physicochemical parameters and properties. Based on a comparative analysis, the main physicochemical parameters and properties of locum masses, obtained with sucrose and isomaltulose, were determined.
\end{abstract}

\section{Introduction}

The Turkish delight is a confectionary product known on the Balkan Peninsula and the Middle East. It has a soft, jelly-like texture, usually available in the form of small cubes [1]. Depending on its composition, in Bulgaria, Turkish delight is divided into two main types: "Ordinary" and "Extra". The main ingredients in the production of "Ordinary" Turkish delight are sucrose, starch (which acts as a gelling agent), glucose syrup and food additives (colorants, flavors and acids). Glucose syrup is not included in the compositions of „Extra“ Turkish delight [2].

Sucrose is one of the main ingredients in the production of Turkish delight. Sugars are an important in foods whose composition includes starch, as they affect properties such as sweetness, texture, color and gelatinization of starch. Various sugars differ in their effect on the ability of starch to jelly [3].

Unhealthy nutrition, along with physical inactivity are identified as major factors in the development of noncommunicable diseases such as obesity, diabetes, cardiovascular disease, osteoporosis and others [4,5]. This is the reason why in recent decades, there is a tendency to replace sucrose in the composition of various groups of confectionery products with suitable alternatives. In this regard, isomaltulose is gaining in popularity.

Isomaltulose is "generally recognized as safe" by the US Food and Drug Administration (FDA) and approved as "Novel Food" in 2005 by the European Union [6-9]. Isomaltulose is defined as a "slow" but fully digestible carbohydrate, which distinguishes it from other sugar alternatives such as tagatose, sugar alcohols and others
[10]. Isomaltulose has a weak effect on blood sugar and insulin levels and is characterized by its low glycemic index $(\mathrm{GI}=32)$ compared to that of sucrose $(\mathrm{GI}=65)$ $[11,12]$. Studies show that blood glucose and insulin concentrations are lower after isomaltulose intake than sucrose [13]. The energy value it provides to the body is $4 \mathrm{kcal} / \mathrm{g}$ like other sugars. Isomaltulose is defined as not causing tooth decay and is the only sugar that is resistant to oral fermentation [10].

There is no information in the bibliography on the replacement of sucrose in the composition of Turkish delight with isomaltulose. [14] present a study in which they have replaced the sucrose in the Turkish delight mass with carob concentrate. It was found that the sample obtained with the participation of $10 \%$ carob concentrate was best perceived by consumers after a sensory analysis. Analyzes have been performed in which fruit syrups as sugar carriers are included in the recipe of Turkish delight [15].

For this reason, the aim of the present study is to establish the possibility of using isomaltulose as an alternative to sucrose in the composition of Turkish delight masses.

\section{Materials and methods}

For the purposes of the research, it was used crystal sugar - Zaharni Zavodi AD Gorna Oryahovitsa; isomaltuloseBENEO-Palatinit GmbH; wheat starch - "Amilum Bulgaria" and glucose syrup - "Cargill" with DE $=38 \%$.

In order to establish the possibility of obtaining "Ordinary" and "Extra" Turkish delight with the

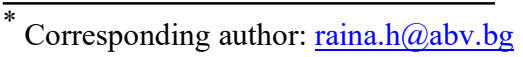


participation of isomaltulose, Turkish delight masses were obtained by compositions shown in Table 1. In order to achieve a comparative characteristic, samples obtained with the participation of sucrose were analyzed, used as controls. For convenience, samples obtained with sucrose are marked as $S_{1}$ and $S_{2}$, and samples obtained with isomaltulose $I_{1}$ and $I_{2}$. The samples were obtained in laboratory conditions with a mass of $1 \mathrm{~kg}$.

Table 1. Composition of Turkish delight.

\begin{tabular}{|l|c|c|c|c|}
\hline \multirow{2}{*}{ Ingredients, \% } & \multicolumn{4}{|c|}{ Sample } \\
\cline { 2 - 5 } & $\mathbf{S}_{1}$ & $\mathbf{I}_{\mathbf{1}}$ & $\mathbf{S}_{2}$ & $\mathbf{I}_{\mathbf{2}}$ \\
\hline Sucrose & 87.90 & - & 67.80 & - \\
\hline Isomaltulose & - & 87.90 & - & 44.75 \\
\hline Glucose syrup & - & - & 21.70 & 44.75 \\
\hline Wheat starch & 11.98 & 11.98 & 10.45 & 10.45 \\
\hline Citric acid & 0.12 & 0.12 & 0.05 & 0.05 \\
\hline Total & $\mathbf{1 0 0}$ & $\mathbf{1 0 0}$ & $\mathbf{1 0 0}$ & $\mathbf{1 0 0}$ \\
\hline
\end{tabular}

The Turkish delight masses are obtained by first preparing the starch milk in a ratio of starch: water - 1: 3 . After maturing the starchy milk, sugar - glucose syrup is boiled. It cools down by adding $10 \%$ water to the weight of the sugar-glucose syrup and dose the starchy milk. The lokum mass is boiled to a dry matter content of the order of $84 \%$ and broken down by intensive homogenization. The finished Turkish delight mass is poured into trays covered with starch and cooled at room temperature. The lokum mass for "Extra" Turkish delight is obtained by the indicated technology, but without the participation of glucose syrup. In samples $I_{1}$ and $I_{2}$, the sugar is replaced by isomaltulose.

The values of the main physicochemical parameters such as dry matter, total sugar, reducing substances and titratable acidity were determined by methods according to [16].

The $\mathrm{pH}$ values of the samples were determined using a $\mathrm{pH}$ meter "Bante". The glycemic indicator was calculated according to a methodology developed by [17].

The color of Turkish delight masses was determined spectrophotometrically at $\lambda=425 \mathrm{~nm}$ on $15 \%$ solutions of the analyzed samples.

The texture of samples was determined using a penetrometer and is expressed in penetration units, which show the immersion depth of a cone with an angle of $45^{\circ}$ in the analyzed sample during the "immersion" $5 \mathrm{~s}$. The texture of the Turkish delight mass was analyzed at a dry matter content of $50 \%, 60 \%, 70 \%$ and $80 \%$.

The adsorption properties of the Turkish delight masses were determined at relative humidity $\varphi=75 \%$ and $\varphi=94 \%$ at room temperature. Saturated $\mathrm{NaCl}$ and $\mathrm{KNO}_{3}$ solutions were used to maintain a constant relative humidity [16].

The analyzes were performed three times and their average value was reflected.

\section{Results and discussion}

The dry matter of the Turkish delight is an indicator that affects the texture of the final product. For this reason, in the process of boiling and with a change in the dry matter content, the change in the hardness of the Turkish delight mass was monitored by determining its penetration.

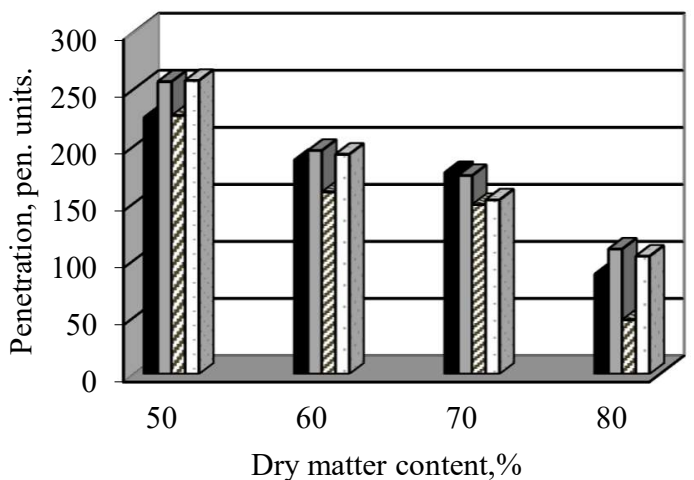

Fig. 1 Texture of Turkish delight masses depending on dry matter content.

Type of sample: - - samples $\mathrm{S}_{1}, \mathbb{\mathrm { S }}$ - samples $\mathrm{I}_{1}$, $\square$ - samples $\mathrm{S}_{2}, \quad \square$ - samples $\mathrm{I}_{2}$

From the data in Fig. 1 it is seen that in all samples there is an increase in the hardness of the Turkish delight mass with an increase in the dry matter content. The lowest penetration was observed in sample $\mathrm{I}_{1}$ at $80 \%$ dry matter content. It was found that the Turkish delight masses intended for the production of "Extra" Turkish delight have a higher hardness than those intended for the production of "Ordinary". This is probably due to the difference in the recipe, namely the presence of glucose syrup in the masses intended for production of "Ordinary" Turkish delight.

Table 2 shows the values of the main physicochemical parameters of the analyzed Turkish delight masses.

Table 2. Physicochemical parameters of Turkish delight masses.

\begin{tabular}{|l|c|c|c|c|}
\hline \multirow{2}{*}{ Indicators } & \multicolumn{4}{|c|}{ Sample } \\
\cline { 2 - 5 } & $\mathbf{S}_{\mathbf{1}}$ & $\mathbf{I}_{\mathbf{1}}$ & $\mathbf{S}_{\mathbf{2}}$ & $\mathbf{I}_{\mathbf{2}}$ \\
\hline $\begin{array}{l}\text { Total sugar content, \% } \\
\text { (as invert sugar) }\end{array}$ & 73.62 & 41.24 & 60.98 & 69.09 \\
\hline $\begin{array}{l}\text { Reducing substances, \% } \\
\text { (as invert sugar) }\end{array}$ & 4.72 & 36.07 & 5.98 & 34.93 \\
\hline $\begin{array}{l}\text { Titratable acidity } \\
\text { (\% like citric acid) }\end{array}$ & 0.03 & 0.09 & 0.02 & 0.06 \\
\hline pH & 4.50 & 4.04 & 5.55 & 5.01 \\
\hline $\begin{array}{l}\text { Coloring, E (15\% } \\
\text { solution; } \lambda=425 \mathrm{~nm})\end{array}$ & 1.52 & 1.60 & 1.44 & 1.62 \\
\hline $\begin{array}{l}\text { Glycemic indicator } \\
\text { (on dry matter) }\end{array}$ & 46.18 & 24.52 & 50.76 & 45.80 \\
\hline
\end{tabular}

The data show that sample $\mathrm{I}_{1}$ has the lowest content of total sugar, but the highest content of reducing substances. Its content of reducing substances is about $87 \%$ higher than that of sample $\mathrm{S}_{1}$. This is probably due to the fact that isomaltulose refers to reducing sugars, unlike sucrose. Sample $\mathrm{I}_{1}$ has about $3 \%$ higher content of reducing substances than sample $\mathrm{I}_{2}$. This small difference is probably due to the higher content of starch and acid in the formulation of sample $\mathrm{I}_{1}$. 
Sample $\mathrm{S}_{1}$ has the highest total sugar content. It is about $41 \%$ higher than sample $I_{1}$ (which has the lowest content). The differences in the samples with regard to this parameter are probably due to the different behavior of sucrose and isomaltulose during acid hydrolysis, the method used, and the different qualitative composition. A significant difference is observed in the values of the calculated glycemic indicator. The sample obtained entirely with isomaltulose $\left(\mathrm{I}_{1}\right)$ has the lowest glycemic indicator, about $50 \%$ lower than sample $\mathrm{S}_{2}$ and about $43 \%$ lower than that of sample $S_{1}$. The higher value of the glycemic indicator of sample $\mathrm{I}_{2}$ is due to the participation of glucose syrup in its composition.

The kinetics of wetting of Turkish delight masses at relative humidity $\varphi=75 \%$ and $\varphi=94 \%$ was monitored. The results are shown in Fig. 2 and Fig 3. The data show that the samples have different behavior under the created storage conditions, for example at $\varphi=75 \%$ only sample $\mathrm{S}_{1}$ absorbs moisture. Similar results were observed [18]. In the other analyzed samples, a decrease in humidity compared to initial was observed. In all analyzed Turkish delight masses, the change in humidity is in the range of $1-1.5 \%$. At $\varphi=94 \%$, only the sample obtained with isomaltulose $\left(\mathrm{I}_{1}\right)$ showed a decrease in humidity compared to the initial. An increase in humidity was observed in all other samples.

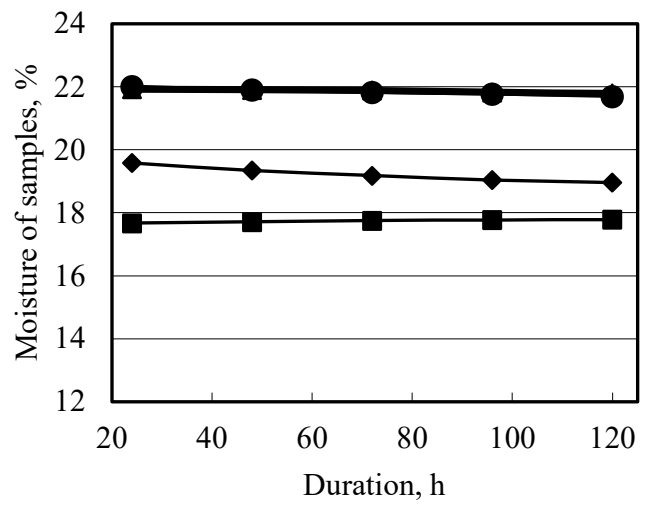

Fig. 2. Kinetics of wetting of Turkish delight masses at $\varphi=75 \%$. Type of sample: - samples $\mathrm{S}_{1}, \boldsymbol{\Delta}$ - samples $\mathrm{S}_{2}$,

$$
\text { - - samples } \mathrm{I}_{1}, \bullet-\text { samples } \mathrm{I}_{2} \text {. }
$$

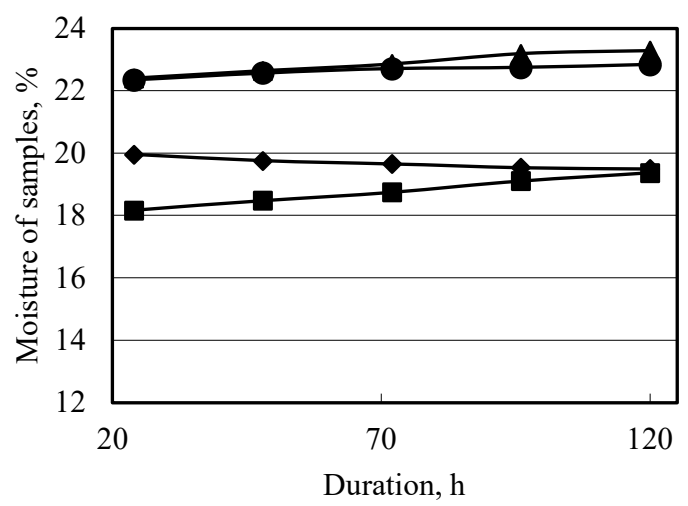

Fig. 3. Kinetics of wetting of Turkish delight masses at $\varphi=94 \%$. Type of sample: - samples $\mathrm{S}_{1}, \boldsymbol{\Delta}$ - samples $\mathrm{S}_{2}$, - - samples $\mathrm{I}_{1}, \quad \bullet$ - samples $\mathrm{I}_{2}$.

\section{Conclusion}

From the performed comparative analysis the influence of isomaltulose as an alternative to sucrose in the composition of Turkish delight masses has been established. It was found that the Turkish delight masses obtained with the participation of isomaltulose $\left(\mathrm{I}_{1}\right)$ has the highest content of reducing substances and the lowest total sugar. This sample also has the lowest glycemic indicator. Regarding the storage of Turkish delight masses at $\varphi=75 \%$ and $\varphi=94 \%$, it was found that the samples have different behavior. The obtained results show that isomaltulose can be a suitable alternative to sucrose in the prescription composition of Turkish delight masses.

\section{References}

1. A. Batu, B. Kirmaci, Food Res. Int. 42, 1-7 (2009)

2. P. Penev, Production of halva and Turkish delight, (EDP Technique, Sofia, 1965)

3. P. Torleya, F. Molen, LWT-Food Sci. Technol. 38, 762-771 (2005)

4. G. Livesey, CUP. 64, 105-113 (2007)

5. A. Astrup, Scand. J. Nutr. 41, 164-167 (1997)

6. I. Holub, A. Gostner, S. Theis, L. Nosek, T. Kudlich, R. Melcher, W. Scheppach, Br. J. Nutr. 103, 17301737 (2010)

7. US Food and Drug Administration. 21CFR \$101.80 Food labelling: health claims: dietary non-cariogenic carbohydrate sweeteners and dental caries. Federal Register, 73, 30299-30301 (2008)

8. EU Commission Decision 2005/581/EC of 25th July 2005 authorising the placing on the market of isomaltulose as a novel food or novel food ingredient under Regulation (EC) no 258/97 of the European Parliament and of the Council. Off. J. Eur. Un. L199, 90-91(2005)

9. US Food and Drug Administration. GRAS Notice No GRN 000184 on isomaltulose. Agency Response letter,http://www.fda.gov/Food/IngredientsPackagin gLabeling/GRAS/Noticeinventory/ucm154643.htm (2006)

10. C. Maresch, S. Petry, S. Theis, A. Bosy-Westphal, T. Linn, Nutrients. 9, 381 (2017)

11. F. Atkinson, K. Foster-Powell, J. Brand-Miller, Diab. Care. 31, 2281-2283 (2008)

12. G. Livesey, Nutr. Res. Rev. 16, 163-191 (2003)

13. J. Otsuka, Y. Okamoto, N. Fujii, Y. Enoki, D. Maejima, T. Nishiyasu, T. Amano, Int. J. Environ. Res. 18, 5760 (2021)

14. R. Ibrahim, F. Abdel-Salam and E. Farahat, Food Sci. Nutr, 11, 757-772 (2020)

15. A. Batu, J. Adv. Mater. Res. 1104, 75-77 (2015)

16. I. Lurie, L. Skokan, P. Tsitovich, Technical and microbiological control in the confectionery industry (Kolos, Moscow, 2003) 
17. A. Dorohovich, V. Kovbasa, M. Gulich, V. Dorokhovych, O. Yaremenko, Method for determining glycemic indicator of a food product (Patent 40623 Ukraine, MPK A 23 L 1/10, 2009)

18. S. Kaya, G. Tattan, J. Food Eng. 7, 186-191 (2017) 